\title{
An Investigation of Historical Structures in Iranian Ancient Architecture
}

\author{
Katayoun Taghizadeh
}

Department of Architecture, University of Tehran, Tehran, 1417466191, Iran

\begin{abstract}
The pre-Islamic styles of Iranian architecture draw on 3-4 thousand years of architectural development from various. Each of the periods of Elamites, Achaemenids, Parthians, and Sassanids were creators of great architecture that over the ages has spread wide and far to other cultures being adopted. Although Iran has suffered its share of destruction, including Alexander the Great's decision to burn Persepolis, there are sufficient remains to form a picture of its classical architecture. This paper featuring a chronological description of structural styles, information on traditional construction materials, as well as an analysis of numerous structures, this interest and informative text will be of importance to anyone with a technical interest in structural history and presents a general overview of the structural and architectural characteristics of Iranian historical structures and investigates historical buildings of Iran through a structural engineering approach. This paper includes a chronological description of architectural styles from the beginning to the end of Sassanid's (before Islam).
\end{abstract}

Keywords Iranian Architecture, Iranian Structures, Dome, Vault, Traditional Structures

\section{Introduction}

The pre-Islamic styles of Iranian architecture draw on 3-4 thousand years of architectural development from various. Each of the periods of Elamites, Achaemenids, Parthians, and Sassanids were creators of great architecture that over the ages has spread wide and far to other cultures being adopted. Although Iran has suffered its share of destruction, including Alexander the Great's decision to burn Persepolis, there are sufficient remains to form a picture of its classical architecture.

Each of the periods of Elamites, Achaemenids, Parthians, and Sassanids were creators of great architecture that over the ages has spread wide and far to other cultures being adopted. Although Iran has suffered its share of destruction, including Alexander the Great's decision to burn Persepolis, there are sufficient remains to form a picture of its classical architecture.

The Achaemenids built on a grand scale. The artists and materials they used were brought in from practically all territories of what was then the largest state in the world. Pasargadae set the standard: its city was laid out in an extensive park with bridges, gardens, colonnaded palaces and open column pavilions.

With the emergence of the Parthians and Sassanids there was an appearance of new forms. Parthian innovations fully

* Corresponding author:

ktaghizad@ut.ac.ir (Katayoun Taghizadeh)

Published online at http://journal.sapub.org/arch

Copyright (C) 2011 Scientific \& Academic Publishing. All Rights Reserved flowered during the Sassanid period with massive barrel-vaulted chambers, solid masonry domes, and tall columns. This influence was to remain for years to come.

\section{Structural Technology in Iranian Architecture}

One of the valuable works of ancient Iranians, they are undoubtedly the remains of construction that remain. Discuss the relationship between structure and architecture of the old argument that professionals and architects, and scholars have spoken a lot about it. In some texts, the structure and architecture is the architecture's past is blurred so that there is no structural separation of the elements of architectural elements. Mehdi Farshad's book tells the history of engineering in Iran:

"History of civilization in the arts, technology and engineering in the form of fiction in Iran as well. Art and technology and engineering knowledge that have been, I have found. Sometimes these courses are common traits has caused them to take the form of joint or separate, but related formats are interdependent."[1]

With a little reflection on the traditional architecture of Iran and some important parts of the world, the combined effect can be seen in different sciences. Harmony between structural and architectural works in this way of thinking is that the unit is in the works. It is possible to imagine to mix to form the separation of structural and architectural elements of the architecture of each other is impossible, because of form, space, geometry, proportions of possible structural 
forms of architecture to have emerged. Spaces created in this work using the human effects are structural elements that are consistent with the demands of the architect.

Employing arches and domes in Iranian traditional architecture of construction and architecture of an intelligent approach in creating architectural space.

"Application forms and promoting understanding of the mechanical indicator dome architecture on the Iranian manufacturers and their knowledge to form and develop high-order value is above the dome-shaped forms."[1]

"This study compared the mechanical and membrane domes form the full curve shows the eleventh century AD, such as engineers in the century, without having in hand a little and modern engineering techniques, intuitive and experimental forms of static and had full knowledge and awareness building."[1]

Important innovations in this direction by architects and builders with regard to the discussions have been static, that most of them are as follows:

1. Truss roofs

2. Diagonal roofs

3. Movable roofs

4. Vault, arch and dome

5. Vaulting without forming

6. Squinch

7. Square Dome (Char Taghi)[1]

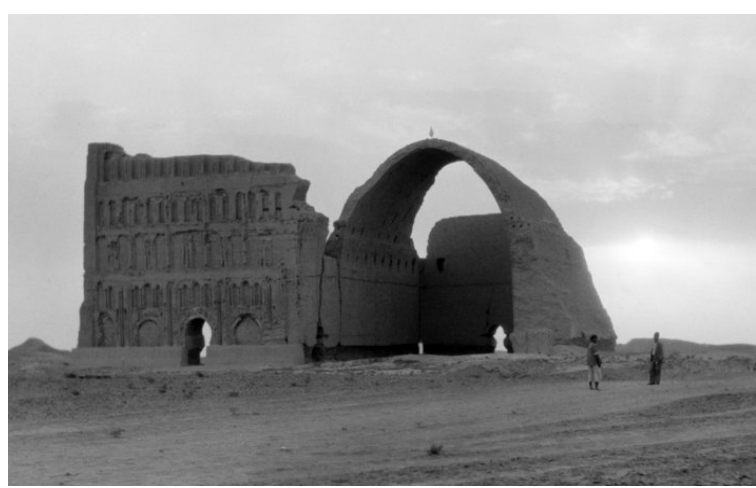

Figure 1. Tagh-i-Kisra 1 on of the oldest arches in the world

The constructor of the architects who were building an important and valuable, both architect and structural engineer and accountant have been, or at least closely related to space and structure is evident in their works.

The works of traditional architecture can be left to the architects to design different shapes and static content. Some work remains in the architecture, the building and construction industry is evident that the idea seems to be the main architect of buildings and structures have shaped the technology. This fact becomes more pronounced when the covering space as a structural element is important and will determine the quality and scale spaces.

In the most of mosques, the space is mainly by the structure of space and what are received are the structural ele-

1 The Tāq-e Kisrā, also called Iwān-e Kisrā, is a Sassanid-era Persian monument in Al-Mada'in which is the only visible remaining structure of the ancient city of Ctesiphon. It is near the modern town of Salman Pak, Iraq. ments. In these works, along with human senses and feel the forces and move them. This fact can be seen inside and outside the buildings. The archways as structural elements in urban spaces, while the structural response needs to define the spatial qualities of the soul represent the integration approach. Using elements such as decorations and Muqarnas and their function in the transmission of forces, reflecting the fact that the architects of the past, well aware of the psychological impact of feeling comfortable in the physical stability and display the load path in different ways.

"When an architect thinks of the work, simultaneously and even more to cover before it is achieved. Things need to cover the mouth of the estuary, volume, weight, and their structure for transmission to the ground and forms the subject sets and the coverage to take the field."[2]

"Coverage is variable. Variable and limited and specified dimensions houseroom, walls and height of buildings based on modules. Architect worthy of spaces, selected to cover them, the proportions in each group, fixed cover and dimensions are given and sometimes arbitrary order. Community with respect to coverage provided to reduce forces. Need to cover, and developed over centuries and ages of the evolutionary process in various ways organs within the architecture and functionality and beauty had reached the peak. In any case to cover the entire architecture of the buildings affected and the most fundamental factor in shaping the organ bearing the architectural spaces."[2]

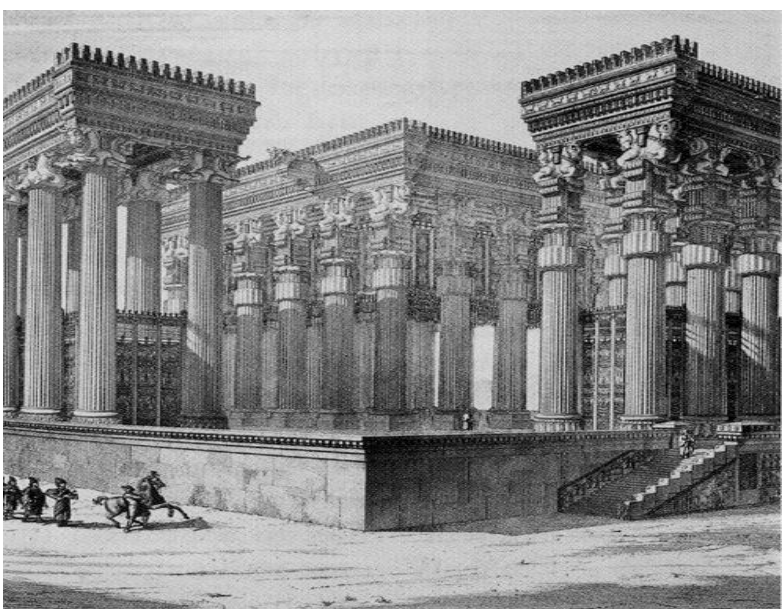

Figure 2. High columns with long distance, Perspolis, Iran

Several examples of important architectural achievements of Iran's Physical mentioned are[3]:

- Structural elements design such as the high columns and long distance between them increases and Shabestans ${ }^{2}$ in Achaemenid architecture, especially in the construction of Persepolis that has been effective in Greece architecture.

- Innovation methods of buildings that form vault and was used from Parthian time, such as making wooden arch with no overall forming.

2 Shabestan or Shabistan is an underground space that can be usually found in traditional architecture of mosques, houses, and schools in ancient Persia (Iran). These spaces were usually used during summers and could be ventilated by windcatchers and qanats. 
- Innovation rectangular space in the dome and construction techniques that depend on creating new spaces. West architecture was very effected by this Iranian innovation.

- Arch and dome construction of the narrow vault, expansion and development in Iran, found its way to other parts of the world

- Double vault construction that nowhere in the world did not spread.

- Construction of various vault structures such as Karbndy which was born in Iran and Expanded.

- Creating different spaces and the expansion and evolution in a time and place in a Continuous course of history, from multi iwans ${ }^{3}$ spaces with the central courtyard to palace.

As mentioned above, in vestigation the traditional structures and architectural structures, several historic examples can be considered. In historic architectural examples in Iran, the relationship between architectural design and structure are inseparable, as if the structure is the same architectural design. It is noted that many works of different periods of Iranian architecture, structure is presented as a design element (except in special cases, the structural elements). Although we cannot distinguish between the structure and architecture, but also defining the structure of space, but the architecture is the same structure.

Examples of such restrictions have been more emphasis on structures of Tarykhanhe mosque ${ }^{4}$ Also Toqrol tower ${ }^{5}$ is designed and implemented that it's structural arrangement of the structures in this research project is intended to better show. . Seljuk architecture of power and originality of expression is without doubt the mosque. Discussion and Analysis of the mosque is very detailed. This discussion of what is desired, use the structures to shape and define the architectural design space.

- Structure as the main element of the design space is used so that the structure is integrated with architectural design.

- The main structural elements necessary to form decorative shapes and geometry to create a rich and abstract forms are smaller. In other words, the structural design, decoration and structural shapes and forms are part of an

3 An iwan is defined as a vaulted hall or space, walled on three sides, with one end entirely open. The formal gateway to the iwan is called pishtaq, a Persian term for a portal projecting from the facade of a building, usually decorated with calligraphy bands, glazed tilework, and geometric designs.

4 Tarikhaneh Mosque is in fact the oldest mosque in Iran belonging to the 1st century after arrival of Islam which still preserves its original shape. This mosque was built during the 8th century A.D. This is an Arabic design but the building material and architecture is Sassanid. This leads us to believe that originally it had been a fire temple during the Sassanid period, and later the mosque was built over its ruins. One column resembling Sassanian architecture at the eastern wing is a proof of this assertion.

5 The tower is in the vicinity of Ray and probably it is the resting abode of Toqrol I of the Saljuqi Dynasty. This tower is in the form of panels and is $20 \mathrm{~m}$. in height. In $1300 \mathrm{AH}$. it had gone under repair, but unfortunately most of its focal elements such as engravings and inscriptions have been destroyed. There is a stone slab on which the date of repair has been noted. overall plan in the works.

- Materials have been used so often in the structural forces that causes structural and decorations authenticity and integrity of the structure.

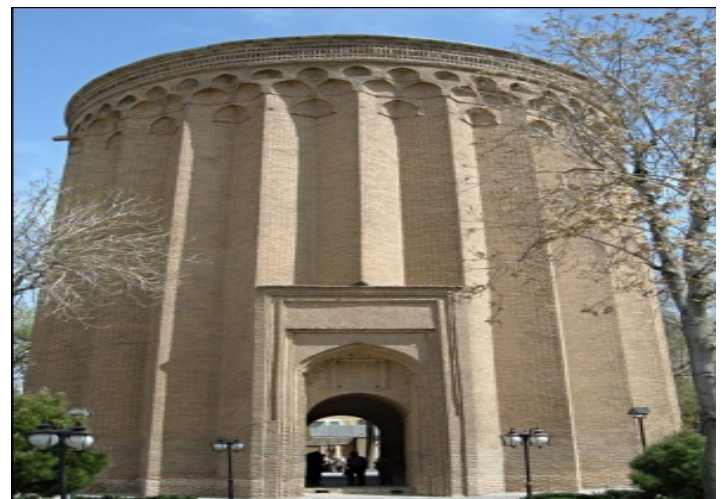

Figure 3. Architectural design and structure in Toqrol tower, Iran

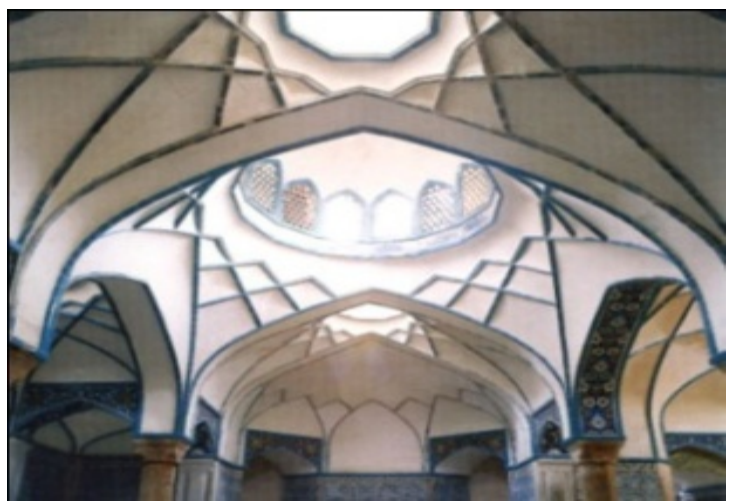

Figure 4. Abstract Geometry, Vakil bath ${ }^{6}$, Iran

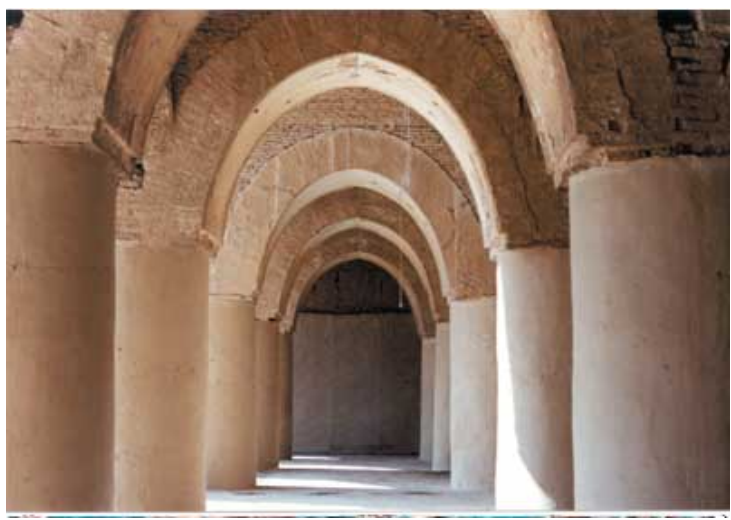

Figure 5. Tarykhanh mosque and emphasis on structure

Modern use of materials displayed on the design and architectural structures and forms of modern architecture in the Seljuk era is interesting. In Malek Rabat and deliberate shows as well as examples of Seljuk art and use of meaningful structural stability.

Structure, architecture and technology joints as a common quality, is created a brilliant eras in architecture. The Khaki dome of the Jame mosque as it related to the year $4781 \mathrm{AH}$

6 Vakil Bath is an old public bath in Shiraz, Iran. It was a part of the royal district constructed during Karim Khan Zand's reign, which includes Arg of Karim Khan, Vakil Bazaar, Vakil Mosque and many administrative buildings. 
(1808 AD), has been praised by researchers around the world in different periods. The Seljuk and Timurid period in Iran because of integrity in architectural design, architecture and technology works can be found valuable. Other notable example can be found in vakil bath in Kerman. . Structure in the dome of the Isfahan Jame mosque and other examples cited not only shows the genius of the craftsmen, but also is remarkable the delicate construction of the brickwork and the abstract geometry of the component designs and to surround the space.

\section{The Seventh Millennium BC to the First Millennium AD}

According to the remaining works of the seventh millennium $\mathrm{BC}$ to the interesting and valuable tips on how to shape the structure and building materials and their transformation in Iranian architecture can be achieved. Some results of these studies is as follows:

- Iranians over the years and have experience in this period thousands of years of experience with a complete stagnation in the development process, have been made significant changes.

- The first human settlements on the Iran plateau, about 9,000 years ago is Sang-e-Chakhmag in Shahrood. It contains elements such as wall-bearing construction and foundation. The walls are made of mud. This building has irregular geometry and architectural spaces and walls have not specified size.

- Thousand years later, in the sixth millennium BC the first mud bricks have been found in Sialk 7 that their dimensions and sizes are relatively large. In this millennium we are witnessing the evolution of the mud bricks production process, clay hence gradually add other materials such as straw, etc.

- In the fifth millennium BC in Tepe Yahya (Kerman) evolution of the clay production process can be seen. In this era mud bricks have fingerprint with a certain order. The first experience on light load bearing wall in this millennium has occurred in central in Iran (Fars) and has been working in interior walls as niche.

- So as past the time, in the fourth millennium BC, mud break became smaller. This size is roughly equivalent to today's bricks. As the bricks size and geometry defined, we also help control the geometry of the components. Geometry miracle occurred in the third millennium BC. In this era regular geometry is clearly seen in the load bearing walls (the building) and rooms (spaces, architecture) of the Burnt City.

- Over 1,000 years, in the second millennium BC, The geometry evolution can be found in sites such Hasanlu, Bastam and .. In this period scale and function of individual

7 Tepe Sialk is a large ancient archeological site (a tepe or Persian tappeh, "hill" or "mound") in a suburb of the city of Kashan, Isfahan Province, in central Iran, close to Fin Garden. The culture that inhabited this area has been linked to the Zayandeh Rud Civilization. buildings change to local community. In order to create large spaces, structural bays are very large, and by using buildings materials such as sized mud bricks, wood and stone, building elements such as load bearing walls, columns, etc and Construction structural systems compound of wall and load bearing structures such spaces are created. From this period onward, all of buildings are mass and large scales are large. The main reason is that materials in the walls of the first millennium $\mathrm{AD}$ is stone and mud that is the first construction materials in the seventh millennium BC, the period is used as mortar.[4]

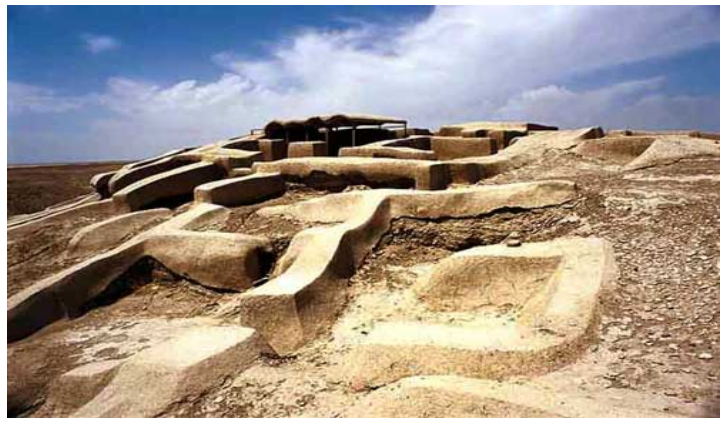

Figure 6. The site of Shahr-i Sokhta, which is Persian for "Burnt City", A Bronze Age city located in the southeast of Iran

\section{Structure and Architecture of the Achaemenid Period}

Architectural building is formed by products contribute a major element in the structure of space and is influenced by cultural factors, social science, technical aspects, climatic and geographical conditions, natural and economic foundations. Close and inevitable relationship between the two elements mentioned had to be looked at from the combination of structure and architecture to Iranian architecture.

In the middle of the sixth century BCE, the Achaemanid clan of the Persians was headed by Cyrus, who ruled, under Median domination, as sub-king of Parsa, or Persis. In 553 BCE Cyrus led a revolt that resulted in the overthrow of the Median ruler and the rise to the power of the Achaemenids. A close union of Persians and Medes soon followed, and an army drawn from these tribal groups embarked on a series of successful campaigns that resulted in the establishment of the first world Empire[5].

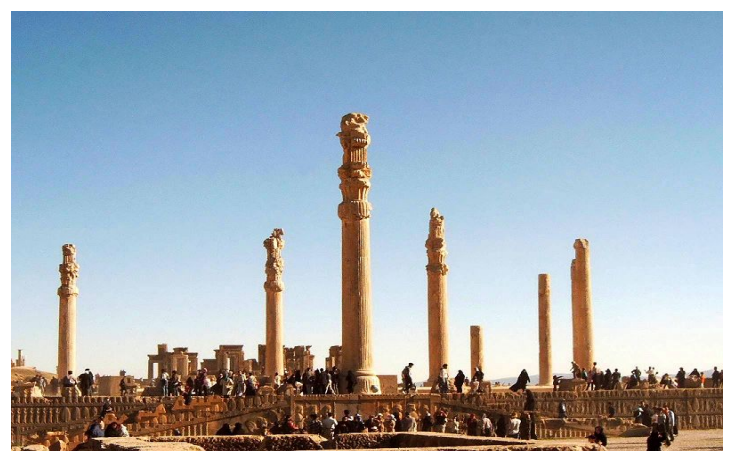

Figure 7. The ruins of Persepolis 
Darius, who became king of the Achaemenid Empire in 521 BCE, ordered construction work at Persepolis in southwestern Iran just two years later. Persepolis, however, situated in the homeland of the Achaemenids was its spiritual center. It was the site of the royal treasury, and every spring the kings came in state to celebrate the festival of the New Year[6]

Table 1. Evolution of Structural systems and materials in Iranian ancient architecture

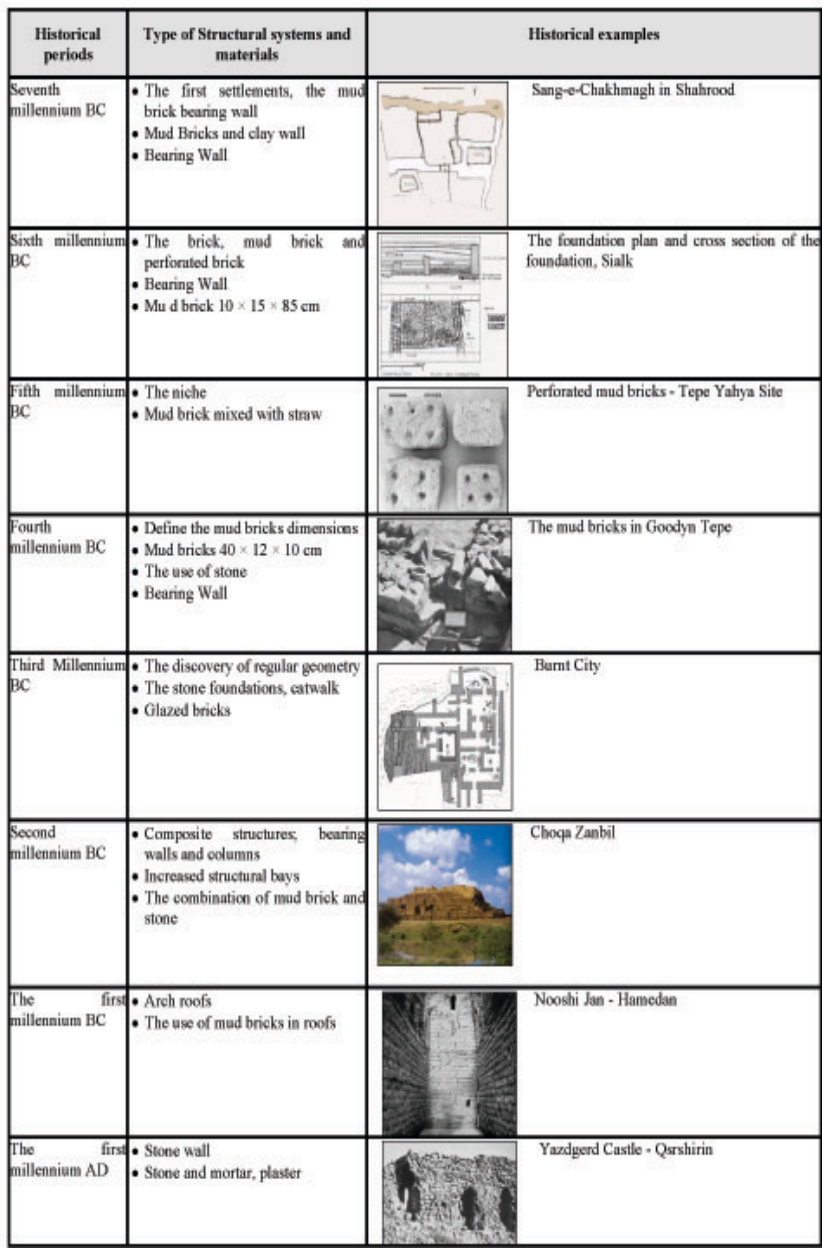

The structures at Persepolis indicate that Achaemenid architecture was a cosmopolitan, eclectic style in which elements and details from many lands had been absorbed and joined. Assyria supplied the concept of the royal structure on a raised platform, certain of the plan forms, the use of colossal bulls, and the composition and style of the incised reliefs. Egyptian architecture furnished specific decorative elements and the profiles of certain of the moldings. Achaemenid inscriptions record that workmen were drawn from every part of the vast empire, as were the materials used, including cedars carried a great distance overland from the famous groves of Lebanon.

During the reign of Achaemenid, architecture providing a variety of spaces needed to be done on the structural system. Space creation with different dimensions in the micro to the macro range and functions are different.

Statics and stability concepts of a combination of stone and wood and mud bricks into compliance with their role in the structural behavior of these materials and materials with the proportion of their technical knowledge of specific structural and deconstruction of materials suitable for load bearing, dead loads (structure self-weight) for stability, structural resistance to applied load proportion, with the height of the structure in order to avoid idleness and balancing, connections with nature are the materials. Therefore the compressive strength of mud brick and stone, usage these materials for vertical walls and columns, and the tensile, compressive and moment resistance (wood), would require it uses as or horizontal elements or beams. In structural systems such as column, beam or frame applied loads using the horizontal or vertical elements is transferred to beams or columns and walls and these elements transfer the load as compressive force to foundations and supports. Weight of the stone columns that could cause some of the horizontal forces, such as resistance to wind forces (the ability to withstand a bending beam or a frame structure on the most suitable geometric form, it is also a member of its genus. For example, if a wooden timber to the width, the bending resistance of a situation in which the timber is located on the thickness). It is interesting to note that this point has been met by manufacturers of wooden beams in Persepolis.

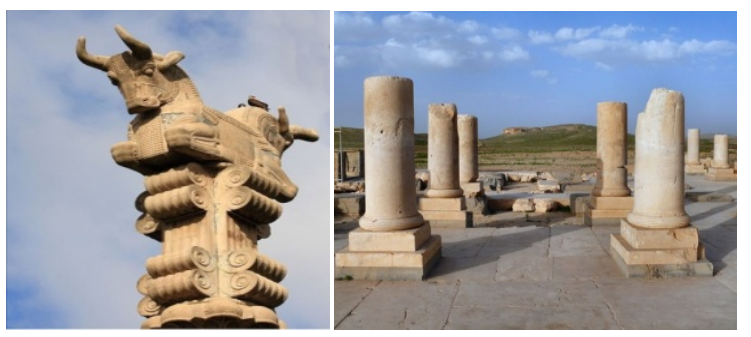

Figure 8. A column combination of three components: pier, body(left) and capital (right)

Stone structures as a column are combination of three components: pier, body and capital and the size and weight of the structure reduced gradually. Weight of the roof, is applied to capitals of columns by wooden beams. In a capital that gradually decrease in thickness from bottom to top, the pieces of the cow's head carved into the wooden beams in the head and the pieces were embedded. From point of view of mechanical stability, building form and force distribution is correct and very interesting.

Also putting together beams to increase the effective surface area for carrying bending force, demonstrate contractors knowledge of mechanical principles. To assemble the parts on each other, the binding sites around the center pillars and columns in place of the notch and groove is carved into the pit, usually the upper part is placed underneath the piece and the connection between Place the cutting material is poured in the glue between the pieces of the stone columns are done. Sometimes connecting the pieces of stone wad done by the iron clamps. Language of stone or brick structures, independent on the wall thickness, dimensions of the load and put the pieces together to finally 
creates a resistant and integrated element[6]

Thus, the architectural considerations such as building materials, structures and culture can be controlled. Thus the space is coexistence, cooperation and spatial composition of the column based on allegorical language and acting in unity with the structural system may occur. The small number of cases determined to become a kind of quality and quality. Although the identity of each column and its location, but independent of their spatial occurrence and that it loses all of the components are not independent, and formed a structure that is capable of resistant to act in such a scale. Using the relationship between any combination of the highest forms of codified and symbolic elements of continuity in their depth, space and structural systems will participate in the state of compliance. This combination and stand firm, and power are a force that is responsible for defining and articulating space. The specific characteristics of a visible through the structural system, the designers of the buildings is the belief that the vertical orientation, forms of codified and widely regarded as the main theme.

So can conclude that if these elements (columns) are removed, not only the structure collapses, it breaks down the space, because the relationship between personality and the nature of the inner and outer space and location of structures and materials is established.

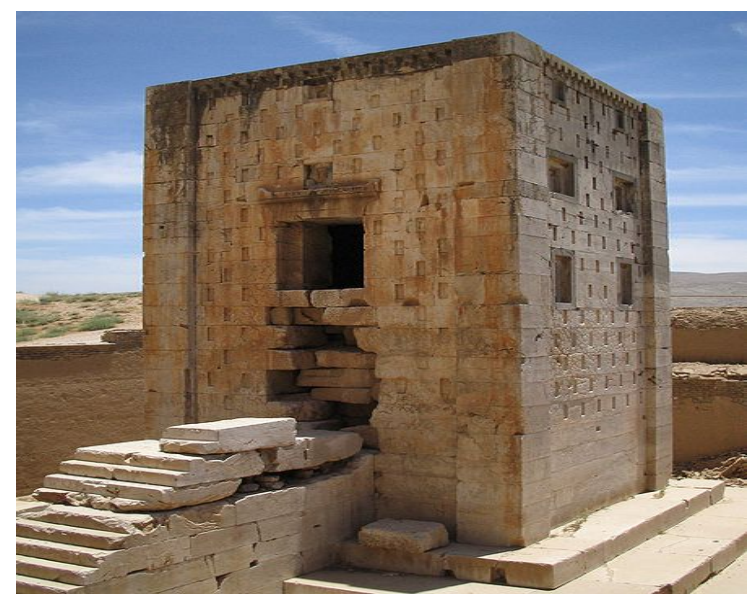

Figure 9. Relationship between architecture and structure as a whole (Kaab-e- zartosht)

\section{Structure and Architecture of the Sassanian Period to the Early Islamic Period}

Sassanid architecture refers to the Persian architectural style that reached a peak in its development during the Sassanid era. In many ways the Sassanid dynastic period (224-651 CE) witnessed the highest achievement of Persian civilization, and constituted the last great Persian Empire before the Muslim conquest. In fact much of what later became known as Muslim culture, architecture, writing and other skills, were taken from the Persians into the wider Muslim world.

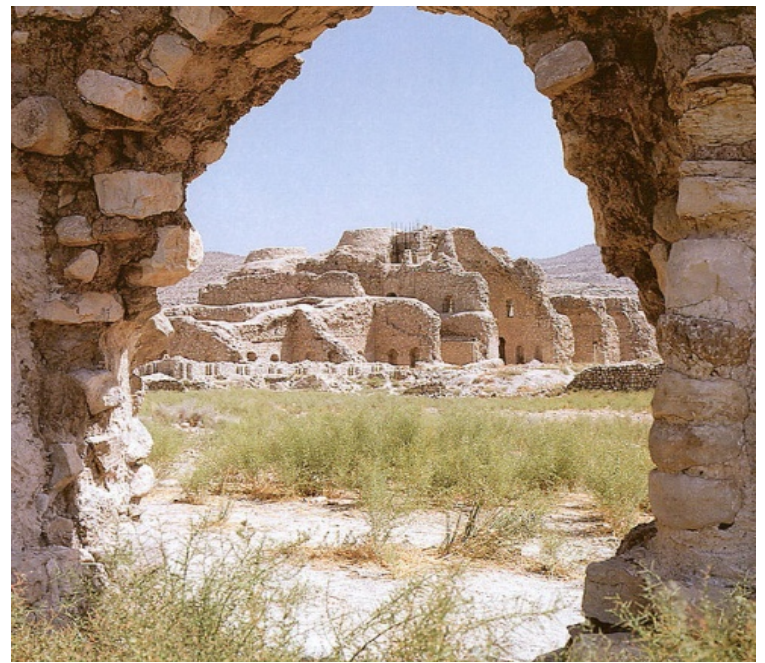

Figure 10. Ardeshir palace in Firouzabad

The splendor in which the Sassanid monarchs lived is well illustrated by their surviving palaces, such as those at Firouzabad and Bishapur in Fars, and the capital city of Ctesiphon in modern Iraq. In addition to local traditions, Parthian dynastic architecture must have been responsible for a great many of the Sassanid architectural characteristics. All are characterized by the barrel-vaulted iwans introduced in the Parthian period, but now they reached massive proportions, particularly at Ctesiphon. The arch of the great vaulted hall at Ctesiphon attributed to the reign of Shapur I (241-272) has a span of more than $80 \mathrm{ft}$, and reaches a height of $118 \mathrm{ft}$. from the ground. This magnificent structure fascinated architects in the centuries that followed and has always been considered as one of the most important pieces of Persian architecture. Many of the palaces contain an inner audience hall which consists, as at Firuzabad, of a chamber surmounted by a dome. The Persians solved the problem of constructing a circular dome on a square building by the squinch. This is an arch built across each corner of the square, thereby converting it into an octagon on which it is simple to place the dome. The dome chamber in the palace of Firouzabad is the earliest surviving example of the use of the squinch and so there is good reason for regarding Persia as its place of invention[7]

The early palaces of the Sassanid have ceased to exist. The most ancient of the Sassanid buildings which admit of being measured and described are assigned to the century between 350 and 450; and we are thus unable to trace the exact steps by which the Sassanid style was gradually elaborated. Features are simple, and are uniform from first to last, the later buildings being merely enlargements of the earlier, by an addition to the number or to the size of the apartments. The principal peculiarities of the style are, first, that the plan of the entire building is an oblong square, without adjuncts or projections; secondly, that the main entrance is into a lofty vaulted porch or hall by an archway of the entire width of the apartment; thirdly, that beside these oblong halls, the building contains square apartments, vaulted with domes, which are circular at their base, and elliptical in their section, 
and which rest on pendentives of an unusual character; fourthly, that the apartments are numerous and en suite, opening one into another, without the intervention of passages; and fifthly, that the palace comprises, as a matter of course, a court, placed towards the rear of the building, with apartments opening into it[8]

In the Sassanian period, vault and transverse arch (ribbed vault) one of the most important inventions in the world of architecture that was invented in this era to solve the openings in the walls that support barrel vault. Widest vault has been built without reinforced masonry and forming (brick and mortar, plaster) in the world, is the Sassanian monument, the vault at Ctesiphon, Iraq, the deficit in the second half of the third century AD.

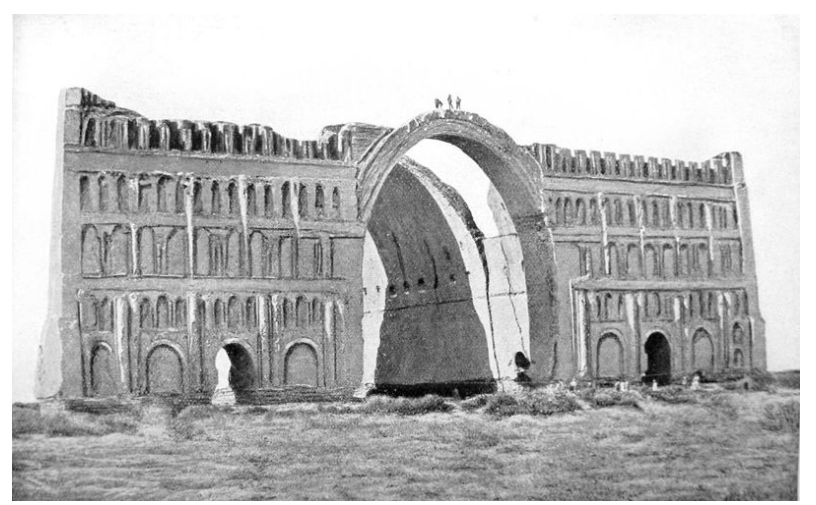

Figure 11. Tagh-e-Kisra, widest vault without reinforced masonry and forming (brick and mortar, plaster) in the world, is the Sassanian monument

After the Achaemenid period, which followed the dome and the necessary technical requirements, covered space for large construction, using wood, was invented during the Parthian, the Sassanian period and the era in building palaces and temples were used and After it was used to cover part of the yard space. It was later used in many mosques and other religious spaces acquire symbolic meaning of the symbols and indications as to be considered religious spaces. Symbolic aspects of the dome was so strong that for the religious aspect of the mosque, used and no element of form has not even imagine such a change takes place, it seems difficult in the near future[9]

Overall the symbolic monuments of the Sassanid dynasty dome evolving growth and development and reached its peak in mosques. Special insight into the dome forms in addition to building value is derived from the other requirements. Dome forms in the viewer is always were considered a sign of divine and metaphysical forces. Stability needs and values to form a dome-shaped sign, which led the Iranian view of history is very rich and fruitful.

One of the issues related to building the dome on a circular base of the dome is a square that Iranian engineers to solve this problem by making a small arc at the corners of the square plan of the polygonal and become a little were to a few side gradually became close to circular shape. The shape of the earrings that became known, the problem was solved.
In buildings of this period is seen frequently in the origin of their product along with the decorative aspects and forms of beauty created them.

\section{Conclusions}

Architecture in Greater Iran has a continuous history from at least 5000BCE to the present, with characteristic examples distributed over a vast area from Syria to North India and the borders of China, from the Caucasus to Zanzibar.

Iranian architecture displays great variety, both structural and aesthetic, developing gradually and coherently out of prior traditions and experience. Without sudden innovations, and despite the repeated trauma of invasions and cultural shocks, it has achieved individuality distinct from that of other Muslim countries. Its paramount virtues are several: a marked feeling for form and scale; structural inventiveness, especially in vault and dome construction; a genius for decoration with a freedom and success not rivaled in any other architecture.

Traditional Iranian architecture has maintained a continuity that, although frequently shunned by western culture or temporarily diverted by political internal conflicts or foreign intrusion, nonetheless has achieved a style that could hardly be mistaken for any other.

\section{REFERENCES}

[1] Farshad, M. (1988), Iranian engineering history, Gooyesh publications, Iran

[2] Abolghasemi, L. (1978), The norm of form finding in Iranian Architecture, Jahad Daneshgahi Publications, Iran

[3] J Pīrniyā, Muammah Karīm (2005), Study of styles in Iranian architecture, Tehran: Surush-i Dānish

[4] Adibzade, B. et al (2006), Iranian residential monuments from Neolithic to Sassanid, The Ministry of Housing \& Urban Development, Iran

[5] Oranskij, I. M. (1977) (in French), Les langues Iraniennes (translated by Joyce Blau), Paris: Klincksieck, ISBN 9-782-252019-91-7

[6] Uphan Pope, Arthur (1982), Introducing Persian Architecture, Tuttle Publications, ISBN 978-0804813662

[7] Farrokh, Kaveh (2008), Shadows in the Desert: Ancient Persia at War, Osprey Publishing, ISBN 978-1846031083

[8] Christensen, A (1939), "Sassanid Persia", in Cook, S. A., The Cambridge Ancient History, 12: The Imperial Crisis and Recovery (A.D. 193-324), Cambridge: Cambridge University Press

[9] Daryaee, Touraj (2009), Sasanian Persia: The Rise and Fall of an Empire. I.B. Taurus 